\title{
Refractory epilepsy in children with brain tumors. The urgency of neurosurgery
}

\author{
Epilepsia refratária em crianças com tumores cerebrais. A urgência de neurocirurgia
}

Marilia Rosa Abtibol Bernardino', Carolina Funayama1, Ana Paula Andrade Hamad', Hélio Machado', Américo Sakamoto', Ursula Thome', Vera CristinaTerra', Antonio Carlos dos Santos ${ }^{1,2,3}$, Luciano Nader

Serafani4 ${ }^{4}$ Nathalia Cunha Calixto², Huria Shalom Monturil de Carvalho Silva ${ }^{4}$

\begin{abstract}
In order to verify indications for surgery, 27 patients with refractory epileptic seizures and brain tumor, aged up to 19 years at the time of surgery, were studied between 1996 and 2013 and followed up for at least one year. The mean interval between the onset of seizures and the diagnosis of the tumor was 3.6 years, and from diagnosis to the surgery, 18 months. The location of the tumor was in the temporal lobe in 16, with ganglioglioma and dysembryoplastic neuroepithelial tumors being the most frequent. Among the patients, $92.5 \%$ and $90.4 \%$ were seizure-free in the first and fifth year after surgery, respectively. Twelve of 16 children were successful in becoming drug-free, with complete withdrawal by 3.2 years. Surgery proved to be potentially curative and safe in these cases, suggesting that the tumor diagnosis and surgery cannot be postponed.
\end{abstract}

Keywords: brain neoplasms; epilepsy; child; adolescent; neurosurgery.

\section{RESUMO}

A fim de verificar os aspectos da indicação cirúrgica, vinte e sete pacientes com epilepsia refratária secundária a tumor cerebral, com idade de até 19 anos na cirurgia, operados entre 1996 e 2013 e seguidos por pelo menos um ano, foram estudados. O intervalo médio entre o início das crises e o diagnóstico do tumor foi de 3,6 anos, e deste para a cirurgia, 18 meses. A localização do tumor foi lobo temporal em 16, sendo ganglioglioma e DNET os tipos mais frequentes. Entre os pacientes, 92,5\% e 90,4\% estavam livres de crises no primeiro e no quinto ano após a cirurgia, respectivamente. Doze de 16 crianças obtiveram sucesso na retirada de drogas, com a média de tempo de 3,2 anos após o procedimento. A cirurgia provou ser potencialmente curativa e segura nestes casos, o que sugere que perante o diagnóstico de tumor esta não pode ser adiada.

Palavras-chave: neoplasias encefálicas; epilepsia, criança; adolescente; neurocirurgia.

Refractory epilepsy, mainly for those patients resistant to drug treatment, has a great impact, causing significant damage to the brain, affecting the development, cognition, learning, behavior and quality of life. Tumors are among the conditions associated with refractory epilepsy, with satisfactory surgical results in children ${ }^{1,2,3,4}$.

A group of a highly epileptogenic brain tumors, called "long-term epilepsy-associated tumors", usually manifest with early onset of spontaneous seizures, and occur predominately in the temporal lobe ${ }^{5}$. Long-term epilepsy-associated tumors are mostly classified as glio-neuronal tumors by the World Health Organization (WHO), are likely to occur during brain development and can be associated with focal cortical dysplasia (International League Against Epilepsy
(ILAE) classification: Type IIIb) ${ }^{6,7,8}$. A tumor manifesting in the temporal lobe in children or adolescents should be carefully examined, as these neoplasms usually belong to the spectrum of long-term epilepsy-associated tumors and not to malignant gliomas. Seizure control should be the primary treatment target to reduce the risk of progressive cognitive impairment or adverse effects of medication and, in order to obtain the best seizure control, surgical treatment is mandatory in these cases ${ }^{5,9}$.

Knowledge about the profile and outcome of patients with epilepsy and brain tumors can assist in making decisions, emphasizing the benefits of a broad discussion between oncology, pediatric neurology, epilepsy and neurosurgery teams.

\footnotetext{
${ }^{1}$ Universidade de São Paulo, Faculdade de Medicina de Ribeirão Preto, Departamento de Neurociências e Ciências do Comportamento, Ribeirão Preto SP, Brasil; ${ }^{2}$ Universidade de São Paulo, Faculdade de Medicina de Ribeirão Preto, Departamento de Neuroradiologia, Seção de Ressonância Magnética, Ribeirão Preto SP, Brasil; ${ }^{3}$ Universidade de São Paulo, Faculdade de Medicina de Ribeirão Preto, Hospital das Clínicas, Centro de Ciências das Imagens e Física Médica, Ribeirão Preto SP, Brasil; 4 Universidade de São Paulo, Faculdade de Medicina de Ribeirão Preto, Departamento de Patologia e Medicina Legal, Ribeirão Preto SP, Brasil.

Correspondence: Marília Rosa Abtibol Bernardino; Faculdade de Medicina de Ribeirão Preto da USP, Departamento de Neurologia; Avenida Bandeirantes, 3900; 14040-900 Ribeirão Preto SP, Brasil; E-mail: marilia.abtibol@gmail.com

Conflict of interest: There is no conflict of interest to declare.
}

Received 16 May 2016; Received in final form 26 July 2016; Accepted 16 August 2016. 


\section{METHODS}

This is a retrospective cross-sectional observational study.

Subjects inclusion criteria were: age less than 19 years at the time of surgery; histopathological exam confirming the nature of the tumor; epilepsy refractory to drug treatment; preoperative evaluation and surgery by the Epilepsy Surgery Center staff of the Hospital of the Ribeirão Preto Medical School, University of São Paulo (CIREP - HCFMRP- USP), surgery between the years 1996 and 2013; follow-up period of a minimum of one year after surgery; medical records containing personal data, clinical and surgical histories recorded clearly and completely.

The use of anti-epileptic drugs (AEDs) was considered, according to the ILAE, as 'appropriate', when AEDs demonstrated efficacy for the epileptic patient's syndrome; 'adequate' when in sufficient doses and for long enough, used alone or in combination, to leave the patient persistently free of seizures; and pharmacoresistant as the failure of two antiepileptic drugs appropriately chosen and tolerated ${ }^{10}$.

The option and choice of a surgical procedure was decided by clinical data analysis and tests (video-EEG, structural and functional neuroimaging) with the participation of a multidisciplinary team of neurologists, neuroradiologists, neurosurgeons, clinical neurophysiologists, neuropsychologists and social workers. Families, legal guardians and patients were informed about the risks and benefits of surgery. The patients were operated on by the same team of neurosurgeons qualified for surgical treatment of tumor and epilepsy. When indicated, intraoperative electrocorticography or invasive preoperative investigation were performed. The resected tissue was sent to the Pathology Service of the HCFMRP-USP. For tumor classification, we used the histological scoring system of the WHO, based on the malignancy level that predicts the biological behavior of cancer.

To categorize the preoperative response to AEDs, the levels set by the ILAE were used: level 1 - patients free of seizures; level 2 - not seizure free; and undetermined - when the information is not sufficient to determine the category ${ }^{10}$. For analysis of outcomes in the incidence of seizures, we relied on the Engel classification, adapted for use after the first year of surgery ${ }^{11,12}$. This includes four classes: class I - free of seizures, class II - rare disabling seizures, class III - marked improvement, but with seizures, and class IV- without a clear improvement. The first, fifth and tenth postoperative years were defined as landmarks for analysis, with the purpose of tracing the clinical outcome of crisis control from the surgery in the short and long term. Descriptive analysis of the data is presented in the Tables.

This project was approved by the Research Ethics Committee of the HCFMRP-USP/Plataforma Brazil, with certificate of introduction to Ethics Assessment: 37388114.6.0000.5440. The researchers had undertaken to comply with the principles expressed in the resolution 12/466 of the Medical Ethics Code.

\section{RESULTS}

Forty-six patients underwent brain surgery in the period between 1996 and 2013. Of these, 19 did not meet the inclusion criteria for this study, as they were older than 19 years at the time of surgery (two patients), the result of the histopathological examination did not confirm the neoplastic nature of the lesion (eight patients), clinical postoperative follow-up was less than one year (two patients), there was no refractory epilepsy (four patients) and incomplete data records (three patients). Therefore, 27 patients were included in the study.

The mean number of AEDs used in the period prior to surgery was 3.6, and at the time of surgery, 2.1 drugs. Clinical features of the patients are presented in Table 1. The characteristics of seizures and drug treatments and the presence of associated lesions are found in Table 2. Table 3 shows the tumor characteristics. Video-EEG finds are listed in Table 4. Previous invasive monitoring to detect the epileptogenic zone was performed in two patients (7.4\%).

Electrocorticography was performed in 10 children (37\%) and monitoring of the motor area in two (7.4\%). The resection was complete in 24 patients (88.8\%). Two patients had partial resection to preserve motor areas, and in a third patient, because of the aggressive behavior of the tumor, an anaplastic oligodendroglioma, that had already infiltrated extensive brain areas. Eleven patients (40,7\%) were treated with lesionectomy and seven (26\%) with extended lesionectomy. Nine $(33,3 \%)$ were submitted to temporal lobectomy and all of them had their mesial temporal lobes structures removed.

Transient neurological changes after surgery were present in five patients (18.5\%): headache and hemiparesis in one child with a high-grade tumor, hemiparesis in two, nerve cranial VI and VII paresis in one, and neuralgic headache at the surgical site in another.

Three patients (11.1\%) had recurrence of the tumor and needed further surgery. Osteomyelitis occurred in one child $(3.7 \%)$ and was the only surgical complication. There were no intraoperative deaths. Death occurred in one child (3.7\%), due to the high degree of tumor (anaplastic oligodendroglioma), two years after surgery.

Follow-up to evaluate recurrence of seizures in the period after the surgery was for an average of 6.8 years (1.6 to 14.1 years). As there was a significant drop in the return of the patients after the fifth year, only the first five years of follow-up were considered for this analysis. During the first year, 25 of the 27 patients had been classified on the Engel scale as class I and, at the end of fifth year, 19 of 21 patients were class I. The two patients, who showed no improvement in the first and fifth year postoperatively, had the highest frequency of seizures in the preoperative evaluation. Five patients (two with ganglioglioma and three with dysembryoplastic neuroepithelial tumors (DNET)) had associated focal cortical dysplasia. All of them, except one, had evolved to Engel class I until the final follow-up. This child began to show refractory seizures (Engel class IV) in the tenth year after surgery. 
Table 1. Clinical features of the sample (27 patients).

\begin{tabular}{|c|c|}
\hline Clinical features & \\
\hline \multicolumn{2}{|l|}{ Gender - N (\%) } \\
\hline Male & $16(59.2)$ \\
\hline Female & $11(40.8)$ \\
\hline \multicolumn{2}{|l|}{ First signs of the brain tumor - N (\%) } \\
\hline Seizures & $26(96.2)$ \\
\hline Other (nausea and vomiting) & $1(3.7)$ \\
\hline \multicolumn{2}{|l|}{ Comorbidities - N (\%) } \\
\hline Migraine & $3(11.1)$ \\
\hline $\begin{array}{l}\text { Panic disorder and separation anxiety with } \\
\text { somatic symptoms }\end{array}$ & $1(3.7)$ \\
\hline Attention deficit hyperactivity disorder & $1(3.7)$ \\
\hline Obesity due to food intake & $1(3.7)$ \\
\hline \multicolumn{2}{|l|}{ Previous medical history - N (\%) } \\
\hline $\begin{array}{l}\text { Perinatal hypoxic-ischemic } \\
\text { encephalopathy }\end{array}$ & $2(7.4)$ \\
\hline Developmental delay & $1(3.7)$ \\
\hline Family history of epilepsy & $12(44.4)$ \\
\hline Family history of cancer & $1(3.7)$ \\
\hline Mental retardation & $1(3.7)$ \\
\hline \multicolumn{2}{|l|}{ Physical examination - N (\%) } \\
\hline Normal & $24(88.8)$ \\
\hline Abnormal & $3(11.1)$ \\
\hline Dysphasia & $1(3.7)$ \\
\hline $\begin{array}{l}\text { Impairment in short and long-term } \\
\text { memories }\end{array}$ & $1(3.7)$ \\
\hline \multicolumn{2}{|l|}{ Ages and intervals (means) - Years (range) } \\
\hline Onset of symptoms & $6 y(3 m-15.8 y)$ \\
\hline Age at the brain tumor diagnosis & 9.7 y $(10 m-16.8 y)$ \\
\hline $\begin{array}{l}\text { Interval between the onset of seizures } \\
\text { and the diagnosis of the tumor. }\end{array}$ & $3.6 y(1 m-14.5 y)$ \\
\hline $\begin{array}{l}\text { Interval between the brain tumor } \\
\text { diagnosis and surgery }\end{array}$ & 1.5 y (days $-7 y)$ \\
\hline Age of patients at surgery & $11.3 y(3 y-17.4 y)$ \\
\hline
\end{tabular}

Table 2. Epileptic seizures and treatment before surgery.

\begin{tabular}{lcc}
\hline Epileptic seizures & $\mathrm{N}$ & $\%$ \\
\hline Frequency & & \\
\hline Daily (many times a day) & 13 & 48.1 \\
\hline Weekly (some times a week) & 11 & 40.7 \\
\hline Monthly (some times a month) & 3 & 11.1 \\
\hline Type & & \\
\hline Complex partial & 27 & 100 \\
\hline Complex partial with secondary generalization & 9 & 33.3 \\
\hline Simple partial & 2 & 7.4 \\
\hline Generalized tonic-clonic & 2 & 7.4 \\
\hline Status epilepticus & 4 & 14.8 \\
\hline Treatment at the time of surgery & & \\
\hline Monotherapy & 5 & 18.5 \\
\hline Polytherapy & 22 & 81.5 \\
\hline
\end{tabular}

Table 3. Tumor characteristics.

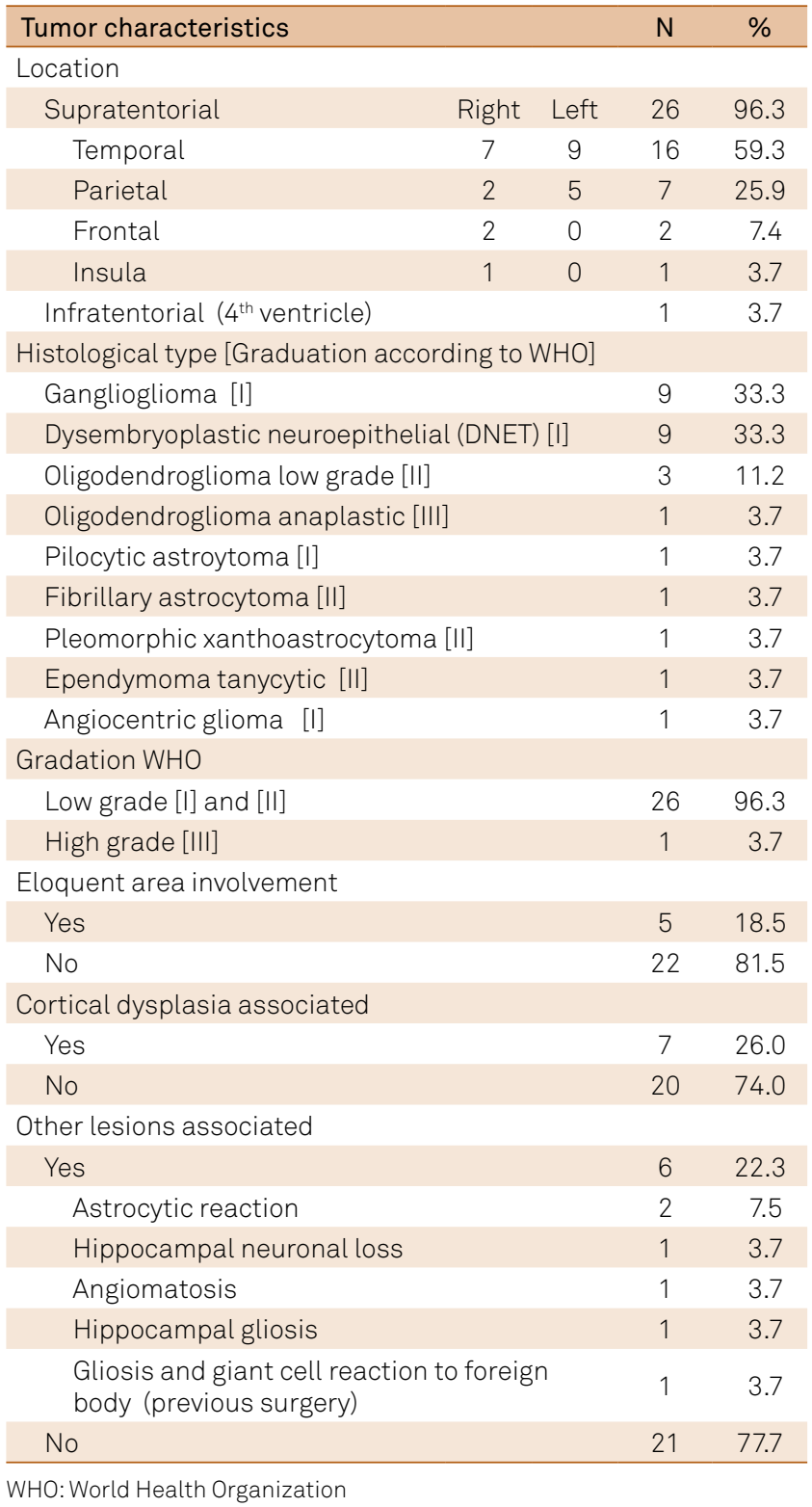

Table 4. Electroencephalographic findings before surgery.

\begin{tabular}{lcc}
\hline Findings & $\mathrm{N}$ & $\%$ \\
\hline Video-electroencephalography & & \\
\hline Abnormal & 26 & 96.3 \\
\hline Normal & 1 & 3.7 \\
\hline EEG background activity & & \\
\hline Abnormal & 9 & 33.3 \\
\hline Normal & 18 & 66.7 \\
\hline Focal slowing & & \\
\hline Present & 17 & 63.0 \\
\hline Absent & 10 & 37.0 \\
\hline Epileptiform activity in relation to the tumor location & & \\
\hline Focal - corresponding to the tumoral area & 23 & 85.2 \\
\hline Multifocal & 1 & 3.7 \\
\hline Generalized & 1 & 3.7 \\
\hline Absent epileptiform activity & 2 & 7.4 \\
\hline
\end{tabular}


After surgery, 16 patients $(59.2 \%)$ started the process of withdrawal of AEDs. The mean time and mode for withdrawal of AEDs in these patients was 3.2 years and two years after surgery, respectively, ranging from 1.7 years to seven years. In these 16 patients, $12(44.4 \%)$ succeeded in staying drug-free, two $(7.4 \%)$ were still in the process of withdrawal, with monotherapy, and the other two (7.4\%) had failed the attempt, with return of the seizures.

\section{DISCUSSION}

The patients in this study were children from the Refractory Epilepsy Outpatient Clinic, and did not reflect routine patients found in the oncology clinic. This explains seizure as the initial manifestation of brain tumor in the majority (96.2\%); only one patient had nausea and vomiting as initial symptoms.

All patients had complex partial seizures. The literature refers to the possibility of brain tumors in a scenario of refractory complex partial seizures, associated with normal neurological examination and preserved intelligence ${ }^{13}$. Epilepsy associated with tumor has great potential for refractoriness to AED treatment ${ }^{14}$. In the present study, the selected patients had epilepsy resistant to drug treatment. However, we should not exclude the possibility of a tumoral etiology in cases of good response to drug treatment, as occurred in four children found during the search for patients in this study.

The interval between the onset of seizures and tumor diagnosis of 3.6 years is above the average delay in diagnosis in relation to other brain tumors ${ }^{15}$. This can be explained by the fact that the vast majority of tumors in the study (96.3\%) were low grade (grade I and II according to WHO). Due to the slow growth of these tumors, seizures can occur even before the tumor is detected by imaging. High-grade tumors are diagnosed in a shorter time due to the more significant symptoms and increased growth rate.

The occurrence of seizures is more common in a supratentorial lesion. Studies differ on the lobe that is more prone to epileptogenesis, but most agree that occipital lesions are less associated with seizure ${ }^{16,17}$. The findings in the present study are consistent with the literature, since the temporal location was the most frequent, and none occurred in the occipital lobe.

There was involvement of eloquent cortex in $18.5 \%$ of children. In the case of low-grade tumors, sometimes in functionally viable brain regions, surgical intervention for tumor treatment is often prohibited or delayed by oncology specialists. On the other hand, for these cases, the work of neuropediatric and epileptology teams is based on the refractoriness of the epilepsy and its impact on the developing child, motivating the preoperative evaluation for epilepsy treatment so that the epileptogenic zone is bounded and removed. Electroencephalographic monitoring techniques are of great importance in further investigation of patients with brain tumor in childhood, taking into account not only the tumor area as a cause of epilepsy, but aiming also to locate peritumoral regions that are also enabling the generation of fires. These techniques also enable a better delineation of the area to be removed, contributing to more favorable outcomes after surgical treatment. All patients in this study were submitted to extended video-EEG, as part of the preoperative assessment protocol, and $3.7 \%$ presented with no changes.

Typical findings of focal epileptic activity corresponding to the area of tumor location and focal slowing were the most prevalent. However, multifocal and generalized epileptic activity were also detected, and in $7.4 \%$ of the patients the epileptic activity was absent. In these cases of nonlocalized changes or those with missing epileptic activity, surgical treatment was indicated because of the neoplastic nature of the lesion. Thus, it can be stated that multifocal or generalized abnormalities, as well as the absence of abnormalities in the EEG, do not exclude the possibility of tumor occurrence ${ }^{2,18}$.

Tumors of glioneural origin, gangliogliomas and DNET were the most frequent in our series and they are included in the long-term epilepsy-associated tumors ${ }^{6,7,8}$. The latter, largely occurring in children and young adults, have the highest rate of association with epilepsy, being $85 \%$ to $92 \%$ in DNETs and $63 \%$ to $91 \%$ in gangliogliomas ${ }^{14,16}$. As its origin suggests, the glioneural tumors consist of dysplastic neurons and neoplastic glial cells. Within these, tumors develop in hyperexcitable regions of dysplastic neurons, which are believed to favor their potential epileptogenesis ${ }^{19}$.

Among the low-grade glial tumors, low-grade oligodendroglioma (11.2\%) was another with significant occurrence in the study. In the group of gliomas, these low-grade tumors are the most likely to generate fires. Recent studies have shown seizures in 50-81\% of astrocytomas and 46-78\% in oligodendrogliomas ${ }^{16,20,21}$. These slowly growing tumors invade the surrounding tissue causing gliosis and chronic inflammation, with changes in peritumoral regions. Evidence of these inflammatory changes is detectable using immunohistochemical techniques, where there is a significant increase in reactive astrocytes in peritumoral cortical tissue of patients with chronic epilepsy compared to peritumoral tissues of patients without seizures ${ }^{17}$.

The only high-grade tumor detected was the anaplastic oligodendroglioma (WHO grade III). The high-grade gliomas (WHO grades III and IV) are associated with a lower rate of seizures. This can be explained more by the short survival time of patients due to the tumor's aggressive nature, than by its epileptogenesis potential ${ }^{16}$. Despite the seizures being less frequent, these are the most difficult to treat and they demonstrate increased refractoriness to clinical treatment and are likely to persist after the surgery. This is probably due to the fire-generating mechanism of these tumors, through local tissue destruction, 
ischemia and necrosis. Because of their growth rate, they can also cause changes in peritumoral regions through their mass effect or disruption of neural networks ${ }^{17}$.

Complete tumor resection in $88.8 \%$ of patients, transient focal neurological deficits after surgery, absence of intra-operative deaths, only one occurrence of surgical complication and the favorable clinical outcomes related to seizure control are findings that encourage the indication for surgery in a tertiary center. Lesionectomy was the surgical technique most used (40.7\%). The seizures caused by long-term epilepsyassociated tumors usually have excellent outcome following appropriate surgical resection, using not only a tumoral, but also an epilepsy surgery-oriented strategy ${ }^{5}$.

The postoperative seizure control was consistent with the literature, where the range of Engel classification class I was from $55 \%$ to $79 \%$, class II from $4 \%$ to $25 \%$ and class III from $4 \%$ to $15 \%{ }^{1,2,3}$. Two of these publications cited $5 \%^{3}$ and $12.2 \%^{2}$ with class IV.

The present work is the second review of cases handled in CIREP. The first ${ }^{22}$ included patients seen up to 2010, with all tumor types, including non-neoplastic findings, in addition to the refractory cases, and a postoperative follow-up period of six months. The most common tumors found in this review were also gangliogliomas and DNETs, together covering $45 \%$ of the total number of tumors diagnosed, and the outcome was significantly positive, both types corresponding to Engel class I in $89.3 \%$. This suggests that the favorable postoperative outcomes in relation to seizures control have remained.

The correlation between the preoperative control of seizures and favorable outcomes after surgery has been well established in the literature ${ }^{20}$. We found that children who showed no postoperative improvement had an increased frequency of seizures in the preoperative evaluation.

A negative outcome in relation to seizure control and death was observed in a child with anaplastic oligodendroglioma, due to the aggressive nature of the tumor (grade III). The patient had a high frequency of seizures in the preoperative period, refractory to anticonvulsant treatment, with a brief interval between the onset of seizures, tumor diagnosis, and surgery. There was no improvement in seizure control after surgery and radiotherapy; this child had Engel class IV one year after surgery, and died in the second year. Another tumor that showed unfavorable outcome regarding seizure control was a fibrillary astrocytoma. This was a type of diffuse astrocytoma that despite being well-differentiated (grade II), the tendency was to become more infiltrative, with evolution to Engel class IV.

Contrary to being a low-grade tumor (grade I), with a good prognosis after surgical treatment, two cases of DNET did not progress favorably in the long-term outcome regarding seizure control. The first case had good response initially, becoming free of seizures in the two years after surgery (Engel class I at one year postoperatively), but destabilized clinically after attempted withdrawal of AEDs in this period, maintaining improvement in relation to their preoperative status, but with recurrence of crippling crises (class III in the fifth postoperative year). The second patient remained free of seizures in the six years following the surgery (class I in the first and fifth postoperative years). He stopped taking two AEDs after the second year, remaining on monotherapy until the sixth postoperative year. At this time, there was clinical decompensation due to tumor growth in residual areas and associated cortical dysplasia, making it necessary to undergo electrocorticography and a new surgery. However, he maintained poor control, with class IV in the 10th year. These two cases illustrate the general trend in epilepsy surgery, when the short-term results tend to be higher than those of the long term. Particularly in the case of children whose seizures are very common and can impact their development, incurring encephalopathies, this temporary seizure control can be considered a positive prognosis.

In the present study, $59.2 \%$ of patients attempted AED withdrawal and among these, $7.4 \%$ relapsed. Successful AED withdrawal occurred in $44.4 \%$ of all patients, without recurrence of seizures in an average of 3.2 years after surgery. There is a need for controlled studies with the goal of examining the best time for withdrawal of AEDs and which factors are involved in the success of the attempts for these cases. The withdrawal of AEDs is a question in many other conditions, each one with particularities to be considered. Recent meta-analysis ${ }^{23}$ enrolled five studies unrelated to epilepsy surgery, showing that for children, the variables associated with higher risk of seizure relapse were: abnormal EEG findings, especially epileptiform activity; epilepsy onset before two years or after 10 years of age; history of status epilepticus; intellectual disability (IQ < 70); and a high seizure frequency before and during treatment. Gender and family history did not show any significant influence over seizure relapse. However, these authors state that the trials included were classified as low or unclear risk of bias where methodological information was not reported and could not be provided by the original study authors.

In conclusion, surgical treatment for refractory epilepsy secondary to tumor etiology had favorable outcomes related both to seizure control, and by improving the response to drug treatment in those who persisted with epilepsy after surgery. The surgery proved to be a potentially curative treatment modality, with temporary postsurgical neurological traits, with no record of intraoperative deaths. Tumor diagnosis cannot be postponed, considering the possibility of curing epilepsy, or in non-curable cases, providing a better response to AEDs, promoting positive impact on the quality of life of children suffering from this debilitating condition. Full preoperative investigation at a referral center for proper location of the epileptogenic zone and electrocorticographic intraoperative monitoring help to assess the origin of the seizures and to prevent impairment of motor and eloquent areas. 
1. Alexiou GA, Varela M, Sfakianos G, Prodromou N. Benign lesions accompanied by intractable epilepsy in children.J Child Neurol. 2009;24(6):697-700. doi:10.1177/0883073808331079

2. Fattal-Valevski A, Nissan N, Kramer U, Constantini S. Seizures as the clinical presenting symptom in children with brain tumors. J Child Neurol. 2013;28(3):292-6. doi:10.1177/0883073812445786

3. Gaggero R, Consales A, Fazzini F, Mancardi MM, Baglietto MG, Nozza P et al. Epilepsy associated with supratentorial brain tumors under 3 years of life. Epilepsy Res. 2009;87(2-3):184-9. doi:10.1016/j.eplepsyres.2009.08.012

4. Cross JH, Jayakar P, Nordli D, Delalande O, Duchowny M, Wieser $\mathrm{HG}$ et al. Proposed criteria for referral and evaluation of children for epilepsy surgery: recommendations of the Subcommission for Pediatric Epilepsy Surgery. Epilepsia. 2006;47(6):952-9. doi:10.1111/j.1528-1167.2006.00569.x

5. Blumcke I, Aronica E, Urbach H, Alexopoulos A, Gonzalez-Martinez JA. A neuropathology-based approach to epilepsy surgery in brain tumors and proposal for a new terminology use for long-term epilepsy-associated brain tumors. Acta Neuropathol. 2014;128(1):39-54. doi:10.1007/s00401-014-1288-9

6. Louis DN, Ohgaki H, Wiestler OD, Cavenee WK, Burger PC, Jouvet A et al. The 2007 WHO classification of tumours of the central nervous system. Acta Neuropathol. 2007;114(2):97-109. doi:10.1007/s00401-007-0243-4

7. Blümcke I, Löbach M, Wolf HK, Wiestler OD. Evidence for developmental precursor lesions in epilepsy-associated glioneuronal tumors. Microsc Res Tech. 1999;46(1):53-8. doi:10.1002/(SICI)10970029(19990701)46:1<53::AID-JEMT5>3.0.C0;2-0

8. Palmini A, Paglioli E, Silva VD. Developmental tumors and adjacent cortical dysplasia: single or dual pathology? Epilepsia. 2013;54(9):18-24. doi:10.1111/epi.12438

9. Santos MV, Oliveira RS, Machado HR. Approach to cortical dysplasia associated with glial and glioneuronal tumors (FCD type IIIb). Childs Nerv Syst. 2014;30(11):1869- 74. doi:10.1007/s00381-014-2519-z

10. Kwan P, Arzimanoglou A, Berg AT, Brodie MJ, Allen Hauser W, Mathern $G$ et al. Definition of drug resistant epilepsy: consensus proposal by the ad hoc Task Force of the ILAE Commission on Therapeutic Strategies. Epilepsia. 2010;51(6):1069-77. doi:10.1111/j.1528-1167.2009.02397.x

11. Engel J Jr et al. Surgical treatment of the epilepsies. 2nd ed. New York: Raven; 1993. p. 609-21.

12. Wieser HG, Blume WT, Fish D, Goldensohn E, Hufnagel A, King D et al. Proposal for a new classification of outcome with respect to epileptic seizures following epilepsy surgery. Epilepsia. 2001;42(2):282-6. doi:10.1046/j.1528-1157.2001.35100.x
13. Blume WT, Girvin JP, Kaufmann JC. Childhood brain tumors presenting as chronic uncontrolled focal seizure disorders. Ann Neurol. 1982;12(6):538-41. doi:10.1002/ana.410120606

14. Aronica E, Leenstra S, Veelen CW, Rijen PC, Hulsebos TJ, Tersmette AC et al. Glioneuronal tumors and medically intractable epilepsy: a clinical study with long-term follow-up of seizure outcome after surgery. Epilepsy Res. 2001;43(3):179-91. doi:10.1016/S0920-1211(00)00208-4

15. Reulecke BC, Erker CG, Fiedler BJ, Niederstadt TU, Kurlemann $G$ et al. Brain tumors in children: initial symptoms and their influence on the time span between symptom onset and diagnosis. J. Child Neurol. 2008;23(2):178-83. doi:10.1177/0883073807308692

16. Hamasaki T, Yamada K, Kuratsu J. Seizures as a presenting symptom in neurosurgical patients: a retrospective single-institution analysis. Clin Neurol Neurosurg. 2013;115(11):2336-40. doi:10.1016/j.clineuro.2013.08.016

17. Berntsson SG, Malmer B, Bondy ML, Qu M, Smits A. Tumor-associated epilepsy and glioma: are there common genetic pathways? Acta Oncol. 2009;48(7):955-63. doi:10.1080/02841860903104145

18. Williams BA, Abbott KJ, Manson JI. Cerebral tumors in children presenting with epilepsy. J Child Neurol. 1992;7(3):291-4. doi:10.1177/088307389200700309

19. Ferrier $\mathrm{CH}$, Aronica E, Leijiten FS, Spliet WG, Huffelen AC, Rijen $\mathrm{PC}$ et al. Electrocorticographic discharge patterns in glioneuronal tumors and focal cortical dysplasia. Epilepsia. 2006;47(9):1477-86. doi:10.1111/j.1528-1167.2006.00619.x

20. Kahlenberg CA, Fadul CE, Roberts DW, Thadani VM, Bujarski KA, Scott RC et al. Seizure prognosis of patients with low-grade tumors. Seizure Eur J Epilepsy. 2012;21(7):540-5. doi:10.1016/j.seizure.2012.05.014

21. Englot DJ, Berger MS, Barbaro NM, Chang EF. Predictors of seizures freedom after resection of supratentorial low-grade gliomas. J Neurosurg. 2011;115(2):240-4. doi:10.3171/2011.3.JNS1153

22. Pinto KGFD. Epilepsia na criança com tumor cerebral: Perfil clínico e evolução dos pacientes tratados cirurgicamente [dissertação]. Ribeirão Preto: Faculdade de Medicina de Ribeirão Preto, Universidade de São Paulo; 2011.

23. Strozzi I, Nolan SJ, Sperling MR, Wingerchuk DM, Sirven J. Early versus late antiepileptic drug withdrawal for people with epilepsy in remission. Cochrane Database Syst Rev. 2015 Feb 12. doi:10.1002/14651858.CD001902.pub2 


\section{Erratum}

Refractory epilepsy in children with brain tumors. The urgency of neurosurgery.

Arq Neuropsiquiatr 2016;74(12):1008-1013. DOI: 10.1590/0004-282X20160157

\section{The authors:}

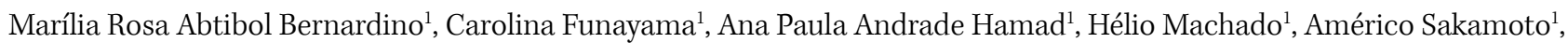
Ursula Thome ${ }^{1}$, Vera Cristina Terra ${ }^{1}$, Antonio Carlos dos Santos ${ }^{1,2,3}$

\section{Should be:}

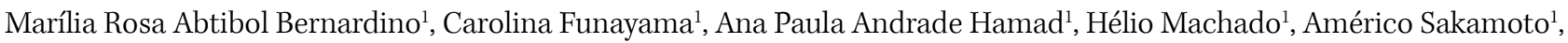
Ursula Thome ${ }^{1}$, Vera CristinaTerra ${ }^{1}$, Antonio Carlos dos Santos ${ }^{1,2,3}$, Luciano Nader Serafani ${ }^{4}$, Nathalia Cunha Calixto ${ }^{2}$, Huria Shalom Monturil de Carvalho Silva ${ }^{4}$

\section{The afiliations:}

${ }^{1}$ Universidade de São Paulo, Faculdade de Medicina de Ribeirão Preto, Departamento de Neurociências e Ciências do Comportamento, Ribeirão Preto SP, Brasil;

${ }^{2}$ Universidade de São Paulo, Faculdade de Medicina de Ribeirão Preto, Departamento de Neuroradiologia, Seção de Ressonância Magnética, Ribeirão Preto SP, Brasil;

${ }^{3}$ Universidade de São Paulo, Faculdade de Medicina de Ribeirão Preto, Hospital das Clínicas, Centro de Ciências das Imagens e Física Médica, Ribeirão Preto SP, Brasil.

\section{Should be:}

${ }^{1}$ Universidade de São Paulo, Faculdade de Medicina de Ribeirão Preto, Departamento de Neurociências e Ciências do Comportamento, Ribeirão Preto SP, Brasil;

${ }^{2}$ Universidade de São Paulo, Faculdade de Medicina de Ribeirão Preto, Departamento de Neuroradiologia, Seção de Ressonância Magnética, Ribeirão Preto SP, Brasil;

${ }^{3}$ Universidade de São Paulo, Faculdade de Medicina de Ribeirão Preto, Hospital das Clínicas, Centro de Ciências das Imagens e Física Médica, Ribeirão Preto SP, Brasil;

${ }^{4}$ Universidade de São Paulo, Faculdade de Medicina de Ribeirão Preto, Departamento de Patologia e Medicina Legal, Ribeirão Preto SP, Brasil.

Aliocha Dostoevski's death during an epileptic seizure.

Arq Neuropsiquiatr 2016; 74 (11): 944-946. DOI: 10.1590/0004-282x20160147

\section{The paragraph:}

However, Anna panicked and called their pediatrician, Dr. A. Tchochin, who lived nearby, picked up the phone immediately. (Page 945)

\section{Should be:}

However, Anna panicked and called their pediatrician, Dr. A. Tchochin, who lived nearby.

\section{Fat embolism showing restriction on diffusion sequence in brain magnetic resonance imaging.}

Arq Neuropsiquiatr 2016;74(7):597-598. DOI: http://dx.doi.org/10.1590/0004-282X20160052

\section{The authors:}

Henry Koiti Sato ${ }^{1}$, Pedro André Kowacs ${ }^{1}$, Josep Dalmau², Paulo Sergio Faro Santos ${ }^{2}$

\section{Should be:}

Henry Koiti Sato ${ }^{1}$, Pedro André Kowacs ${ }^{1}$, Paulo Sergio Faro Santos ${ }^{1}$

The afiliation "'Universitat de Barcelona, Institut D’Investigacions Biomédiques August Pi I Sunyer, Hospital Clínic, Barcelona, Spain." must be ignored. 